Archive for

Organic Chemistry

Arkivoc 2018, part vii, 0-0

\title{
(E)-2-(hydroxystyryl)-3-phenylquinazolin-4(3H)-ones: synthesis, photochemical and luminescent properties
}

\section{Grigory A. Kim, ${ }^{a}$ Irina G. Ovchinnikova, ${ }^{a}$ Emiliya V. Nosova, ${ }^{b}$ Gennady L. Rusinov, ${ }^{a, b}$ Valery N. Charushin ${ }^{a, b}$}

a I. Postovsky Institute of Organic Synthesis, Ural Division, Russian Academy of Sciences, S. Kovalevskoy Str., 22, Ekaterinburg, 620041, Russia

${ }^{b}$ Ural Federal University named after the First President of Russia B.Eltsin, Mira St. 19, Ekaterinburg, 620002, Russia

E-mail: kim-g@ios.uran.ru

\section{Abstract}

The new (E)-2-(hydroxyarilethenyl)-3-phenylquinazolin-4(3H)-ones with various substituents in phenyl fragment were synthesized. The effect of electron donor and acceptor substituents $( \pm M)$ in quinazolinones on luminescence intensity and dual emission in 550-650-nm wavelength range was shown. The fact of the reversible photo/thermal $E-Z$ isomerization for several substances was established. The (E)-2-(5-chloro-2hydroxystyryl)-3-phenylquinazolin-4(3H)-one had shown the best combination of photochemical (E-Z isomerization) and photophysical properties. The (E)-2-(2-hydroxy-5-morpholinostyryl)-3-phenylquinazolin$4(3 H)$-one had revealed the best ESIPT-luminescence $\left(\Phi_{\text {rel }}=5.3 \%\right)$.

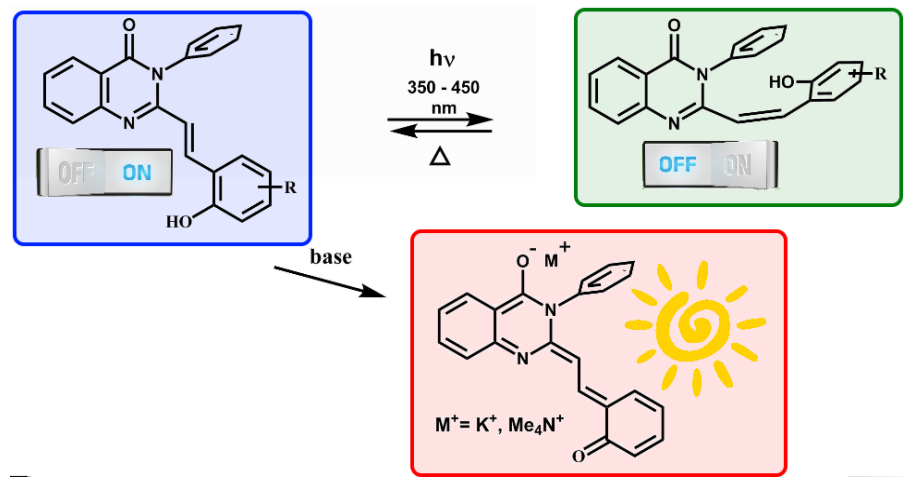

Keywords: (E)-2-(Hydroxystyryl)quinazolinones, ESIPT-luminescence, photoacids, reversible photo/thermal isomerization, photoswitching 


\section{Introduction}

Diarylethenes and its heterocyclic analogues form the basis of modern electroluminescent and photochromic materials, widely used in nonlinear optics, lasers with tunable frequency, optoelectronic devices for recording and storage of information, and molecular photoswitches ${ }^{1,2}$. Unsymmetrical derivatives are of great interest among hetarylstylbenes ${ }^{3}$. The presence of acceptor azine (azinone) core in combination with donor (aryl) fragment in stilbene molecules might considerable influence the photochemical and photophysical properties of luminophores because of the $n, \pi^{*}$ state contribution ${ }^{4}$. However, the amount of publications devoted to the study of unsymmetrical (het)arylethens is not as numerous as for symmetric ones ${ }^{3}$. There are several publications concerning the synthesis of $(E)$-2-styrilquinozaline-4(3H)-ones and studying of their photophysical properties $^{3,5-9}$. It should be noted that compounds of this push-pull type possessing a specific emission ability and a profound tendency to a photoinduced $E$-Z-isomerization ${ }^{8,9}$ are quite promising for the development of base- and acid-sensitive photochromic materials. Our researches have shown that the incorporation of the hydroxyl group in the ortho position of the arylethenyl fragment of quinazolinones 3 (Scheme 1$)^{10,11}$, generates photocontrolled processes like ESIPT luminescence ${ }^{12}$ with a typical broadband spectrum in visible 400-600-nm wavelength range and reversible $E-Z$ isomerization of the vinylene moiety. Appropriate mechanisms of proton transfer in excited state (ESIPT) to the diazinone fragment and back in the course of tautomeric transitions in the conjugated chromophore system were proposed. In this communication we wish to report about influence of donor and acceptor substituents in phenol fragment of $(E)$-2(hydroxyarylethenyl)-3-phenylquinazolin-4(3H)-ones on ESIPT and geometric isomerization of chromophore system. Such system may be useful for white-light emitting materials.

\section{Results and Discussion}

The $\mathrm{C}=\mathrm{C}$ bond formation techniques in the series of (het)arylstilbenes have often a specific nature, while condensation of 2-methylazines ${ }^{4}$ with aromatic aldehydes in the presence of zinc chloride or sodium acetate does not provide high yields of the target compounds. We have established that using boric acid as the catalyst in the proposed method (Scheme 1) ${ }^{11,12}$ afford to synthesize 2-(arylethenyl)-3-phenylquinazolin-4(3H)ones with various acceptor and donor functional groups, including hydroxyl ones, with yields from moderate to excellent. Synthesized substances are the E-isomers. The trans-isomerization of 3a-f is confirmed by the presence of doublets of vicinal protons of $C=C$ bonds in range of $\delta 7.79-8.25$ and $6.14-6.75$ ppm with the spin-spin coupling constant of $\sim 15.5 \mathrm{~Hz}$ in their ${ }^{1} \mathrm{H}$ NMR spectra.

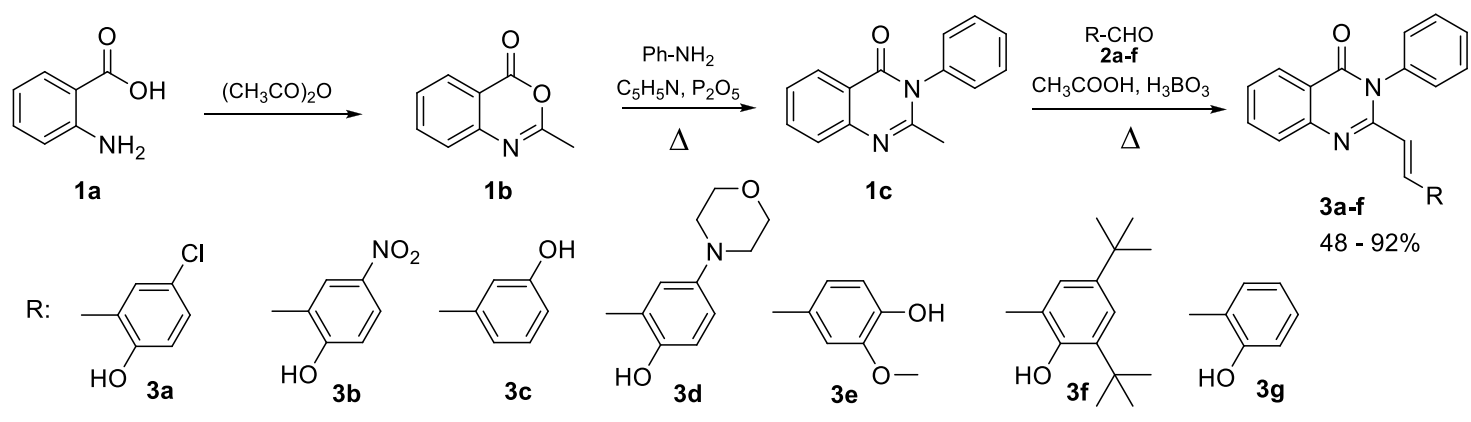

Scheme 1. Synthesis of (E)-2-(hydroxyarylethenyl)-3-phenylquinazolin-4(3H)-ones. 


\section{Photophysical properties of luminophores 3}

The photophysical properties of phenols have been studied by UV-Vis in neutral, basic ( $\mathrm{Me}_{4} \mathrm{NOH}$ and $t$-BuOK) and acidic $\left(\mathrm{CH}_{3} \mathrm{COOH}\right)$ solutions in DMF. In neutral DMF solutions the compounds 3a-f exhibited similar spectral characteristics with absorption maxima in the range $340-400 \mathrm{~nm}$. Compared to the $355-\mathrm{nm}$ absorption maximum of model ortho-hydroxystyryl substituted $\mathbf{3} \mathbf{g}^{10}$, the absorption bands in UV spectra of the compounds 3a-f demonstrate the following differences. The electron-donor groups $(+M)$ in compounds $\mathbf{3 a}$, 3f and $3 e$ compounds provide bathochromic shift of this absorption maximum up to 3-10 $\mathrm{nm}$. The presence of morpholine fragment in quinazolinone $3 \mathrm{~d}$ structure leads to a splitting of the absorption band with the emergence of a long-wave shoulder at 365-480 $\mathrm{nm}$. On the contrary, the electron withdrawing nitro group in $\mathbf{3 b}$ and $\mathrm{OH}$ group in the meta position of $\mathbf{3 c}$ provide hypsochromic shift up to $\sim 12 \mathrm{~nm}$.

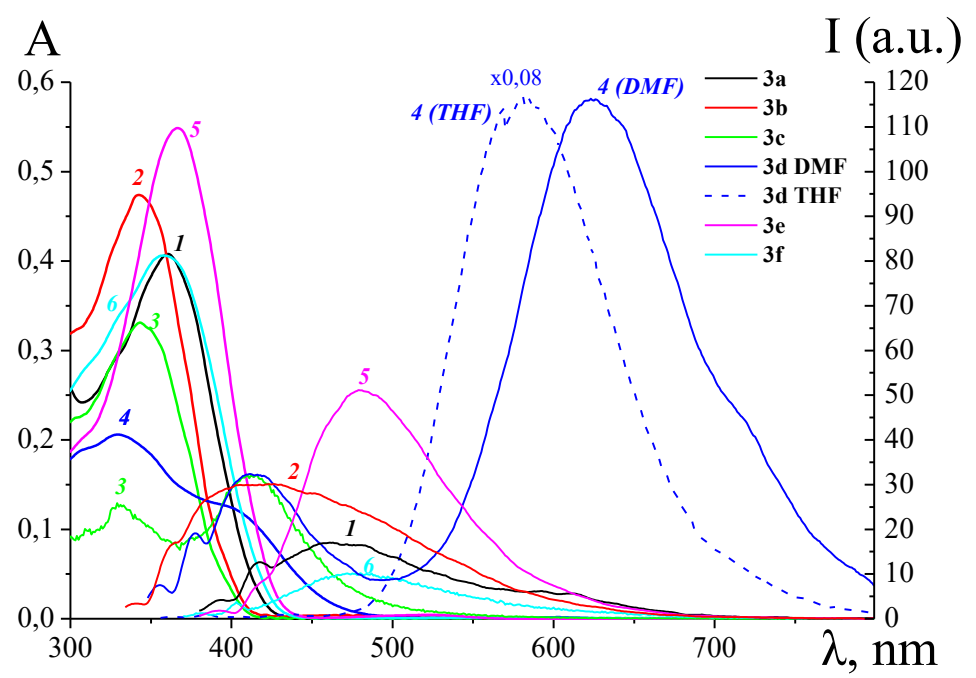

Figure 1. The electron absorption spectra and fluorescence emission spectra ( $\lambda_{\mathrm{ex}}$ in the table 1$)$ of solutions of compounds $E-3\left(2 \cdot 10^{-5} \mathrm{~mol} \mathrm{~L}{ }^{-1}\right.$, in DMF), $E-3 \mathbf{a}(1), E-3 \mathbf{b}(2), E-3 \mathbf{c}(3), E-3 \mathbf{d}(4), E-3 \mathbf{e}(5), E-3 \mathbf{f}(6)$.

Fluorescence spectra of the neutral solutions E-3 demonstrate the following features. The OH group in the ortho and para positions of the phenolic moiety, which is included in the common conjugation chain, leads to a significant broadening of the emission band in the 400-700-nm region compared with that for the meta substituted $E-3 c$ ( 400-530 nm). At the same time, a bathofluoric shift of the emission band maximum from $420 \mathrm{~nm}$ to $485 \mathrm{~nm}$ is observed upon the transition from the electron withdrawing nitro derivative $E-3 \mathrm{~b}$ to the $E-3 \mathbf{a}, E-3 \mathbf{f}$ and $E-3 \mathbf{e}$ with electron donor substituents $(+M)$. It was previously shown that $E-3 \mathbf{g}$ and its alkoxy derivatives have dual emission in neutral media ${ }^{10,11}$ associated with proton transfer in molecules in the excited state (ESIPT). This process is characterized by the emergence in the spectra of long-wavelength emission bands in the $500-700 \mathrm{~nm}$ region with large Stokes shift values $\left(\geq 6000 \mathrm{~cm}^{-1}\right)^{12}$ due to the free phenolate-anion and quinonoid-anion forms that are present in solutions along with an excited undissociated phenol form. The quinazolinones $E-3 \mathbf{a}$ and $E-\mathbf{3 d}$ in neutral media demonstrate the similar behavior. In the emission spectrum of $E-3 a$, like of $E-3 g$, an excited undissociated phenol form $\mathbf{A}$ (normal Franck-Condon excited state) and quinonoid-anion form $\mathbf{B}(\mathbf{C})$, which are in protolytic equilibrium in photostationary state solutions (PSS), are characterized by maxima at 445 and $600 \mathrm{~nm}$, respectively (Figure 1, Scheme 2). In irradiated solutions of E-3d the equilibrium is totally shifted to the free phenolate-anion and quinonoid-anion forms (Figure 1, Scheme 2) with emission band maximum at $625 \mathrm{~nm}$ in DMF or at $583 \mathrm{~nm}$ in THF, like for the ortho-hydroxystyryl 
substituted $E-3 \mathbf{g}$ in $\mathrm{Et}_{3} \mathrm{~N}$ solutions ${ }^{11}$. Apparently, the formation of quinonoid-anion form $\mathbf{G}$ is directly related to the transfer of the proton to the morpholine nitrogen atom in the excited planar conjugated chromophore $E$ 3d to form the morpholinium zwitterion D (Scheme 2). These arguments are confirmed by quantum-chemical calculations according to which the amino group is involved in the electron density of the chromophore HOMO localized on the phenol fragment (S-Table 3). It is worth noting a certain hypsochromic shift of the emission maximum by $42 \mathrm{~nm}$ in irradiated solutions of $E$-3d in THF, compared with that in DMF, and an increase by two orders of emission intensity with quantum yield of $5.3 \%$ ( $\leq 0.1 \%$ for the other substances). These differences observed in the spectra can be explained by the predominance of the free phenolate-anion form $\mathbf{G}$ in equilibrium medium (Scheme 2).

Table 1. Photophysical and photochemical characteristics of quinazolinones $E-3$ in DMF

\begin{tabular}{|c|c|c|c|c|c|c|c|c|}
\hline \multirow[t]{2}{*}{ Compound } & \multirow[t]{2}{*}{$\lambda_{\mathrm{ex}} / \mathrm{nm}$} & \multicolumn{2}{|c|}{$\lambda_{\mathrm{f}} / \mathrm{nm}$} & \multirow{2}{*}{$\begin{array}{l}\text { Stokes } \\
\text { shift } / \mathrm{cm}^{-1}\end{array}$} & \multicolumn{2}{|l|}{$\lambda_{\max (\text { abs })}{ }^{a} / \mathrm{nm}(\varepsilon)$} & \multirow[t]{2}{*}{$t_{E-Z}^{b / s}$} & \multirow[t]{2}{*}{$t_{Z-E}^{c / m}$} \\
\hline & & & & & Starting & Reaction & & \\
\hline \multirow{3}{*}{$E-3 a$} & & & & & & & & \\
\hline & 358 & 455 & 600 & 5955 & 360 (20380) & 359 (17855) & 20 & 40 \\
\hline & & & & 11267 & & & & \\
\hline$E-3 b$ & 342 & 420 & & 5430 & $348(21950)$ & 309 (17715) & 180 & 40 \\
\hline$E-3 c$ & 343 & 411 & & 4823 & $343(16565)$ & $343(14720)$ & 18 & - \\
\hline \multirow[t]{2}{*}{$E-3 d$} & 338 & 625 & 583 & 9000 & $329 \quad(10295)$ & - & - & - \\
\hline & & (THF) & & 7847 & $400(6040)$ & & & \\
\hline$E-3 e$ & 365 & 485 & & 6191 & $356(21730)$ & $348(10835)$ & 12 & 80 \\
\hline$E-3 f$ & 356 & 475 & & 6925 & $358(20345)$ & $316(10760)$ & 16 & 30 \\
\hline \multirow[t]{2}{*}{$E-3 g$} & 358 & 455 & 600 & 5955 & $358(20100)$ & 358 (9950) & 16 & 40 \\
\hline & & & & 11266 & & & & \\
\hline
\end{tabular}

${ }^{a}$ The absorption maxima and the corresponding extinction coefficients [14] $\left(\mathrm{L} \mathrm{mol}^{-1} \mathrm{~cm}^{-1}\right)$ of $3\left(2 \cdot 10^{-5} \mathrm{~mol} \mathrm{~L}^{-1}\right)$. ${ }^{b}$ Duration of photochemical $E-Z$ isomerization of solutions upon exposure to irradiation.

${ }^{c}$ Duration of thermal $Z-E$ isomerization of solutions thermostated at $75{ }^{\circ} \mathrm{C}$

The validity of the assignment of 600-nm long-wavelength luminescence to the quinonoid-anion form is confirmed by the spectral data of titration of $E-3$ solutions with $t-\mathrm{BuOK}$ and $\mathrm{Me}_{4} \mathrm{NOH}$ bases. Similarly to $E-3 g^{11}$, significant changes associated with redistribution and appearance of a new absorption band in the 400-500 $\mathrm{nm}$ visible wavelength range are observed in spectra of $E-3$ basic solutions with the exception of $E-3 c$ and $E$ 3d. The luminescence spectra demonstrate high intensity $600-\mathrm{nm}$ emission band. These changes are related to the tautomeric transformation of conjugated system $E-3$ into the quinonoid form $E-4$ (Scheme 2, Table 2, Fig. 2) and the formation of charge transfer complexes. Earlier obtained results of 2D homo- and heteronuclear NMR experiments in the case with steady-state basic solutions of $E$-3g had unequivocally confirmed the formation of the quinonoid form $E-\mathbf{4 g}$ with the transfer of a negative charge from the phenolate anion to the oxygen atom of the keto-group ${ }^{10}$ (Scheme 2). Similar changes of proton signal positions occur in ${ }^{1} \mathrm{H} N M R$ spectra, e.g. E-3a (Experimental Section, S-Fig. 1). Consequently, a significant luminescence at $600 \mathrm{~nm}$ has been the result of the direct excitation of the quinonoid-anion form $E-4$ (similarly $E-3 g^{10}$ ) and exhibited a normal Stokes' shift ( $\Delta v 1665$ - 5327) and high quantum yield (Table 2). The quantum yield of chlorine substituted $E$-3a reaches the highest values (23.4\%) and its decrease by two orders for $E$-3b is caused by luminescence quenching because of nitro group. 


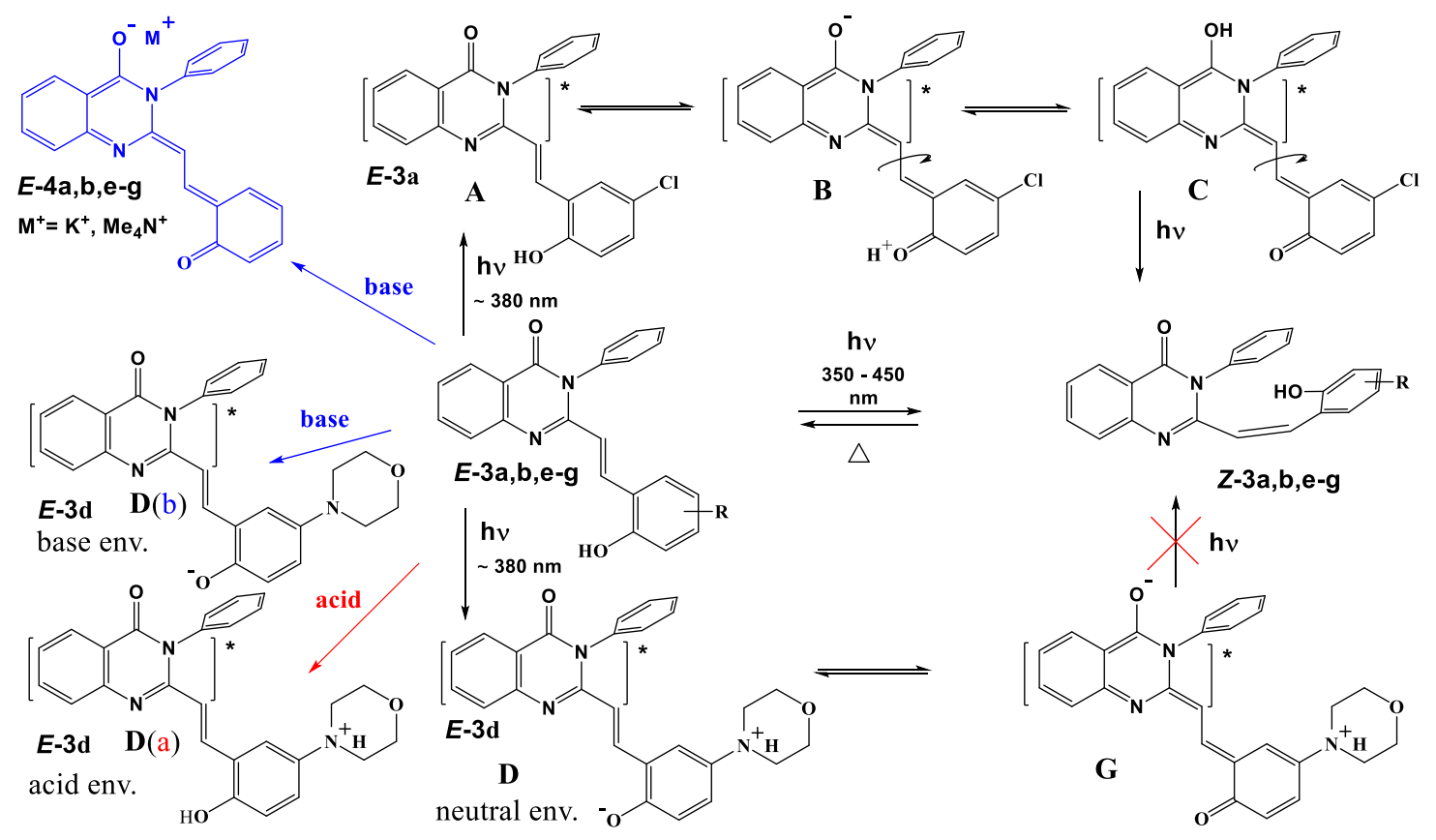

Scheme 2. Photophysical and photochemical processes in (E)-2-(hydroxyarylethenyl)-3-phenylquinazolin$4(3 H)$-ones.

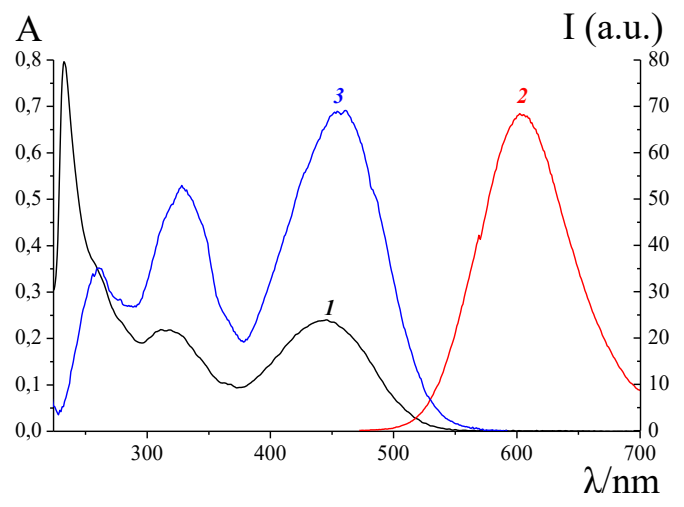

Figure 2. The electron absorption (1), fluorescence emission (2) and excitation (3) spectra of the quinonoid form of $E-3 a\left(2 \cdot 10^{-5} \mathrm{~mol} \mathrm{~L}^{-1}\right)$ in DMF after the addition of $\mathrm{Me}_{4} \mathrm{NOH}$ in the molar ratio of 1:20 (excitation and emission wavelength, $\lambda / \mathrm{nm}: 457$ and 605 , respectively).

Table 2. Selected photophysical characteristics of the quinonoid form $E-4$ of $E-3\left(2 \cdot 10^{-5} \mathrm{~mol} \mathrm{~L}^{-1}\right)$ in basic media (DMF and $\mathrm{Me}_{4} \mathrm{NOH}$ or $t$-BuOK), $C_{E-3}: \mathrm{C}_{\text {base }}$ as 1:20.

\begin{tabular}{llllll}
\hline Compound $\left(2 \cdot 10^{-5} \mathrm{~mol} \mathrm{~L}^{-1}\right)$ & $\lambda_{\mathrm{abs}} / \mathrm{nm}$ & $\lambda_{\mathrm{ex}} / \mathrm{nm}$ & $\lambda_{\mathrm{em}} / \mathrm{nm}$ & Stokes' shift $/ \mathrm{cm}^{-1}$ & $\Phi_{\text {rel }}(\%)$ \\
\hline 4a & 443 & 457 & 604 & 5327 & 23,4 \\
4b & 490 & 505 & 555 & 2390 & 0,2 \\
3c & 337 & 276 & 385 & 3699 & - \\
3d & $329(400$ shoulder $)$ & 338 & 625 & 9000 & 0.8 \\
4e & 513 & 518 & 567 & 1856 & 0.3 \\
4f & 548 & 580 & 642 & 1665 & 12,2 \\
4g & 520 & 520 & 607 & 2757 & 12,5 \\
\hline
\end{tabular}




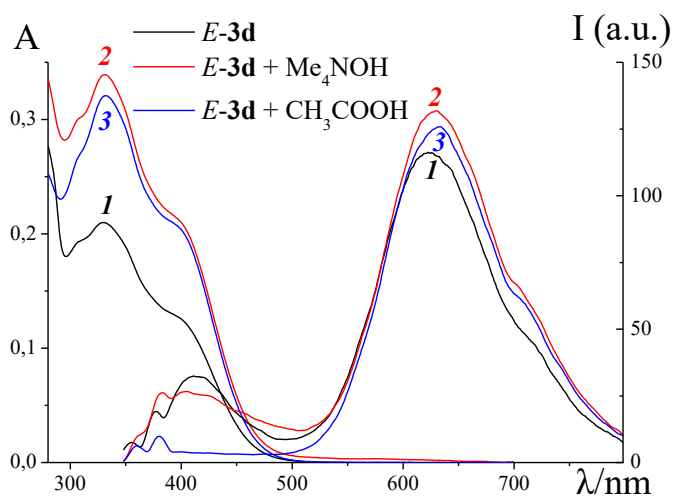

Figure 3. The electron absorption and fluorescence emission spectra $\left(\lambda_{\mathrm{ex}} \sim 338 \mathrm{~nm}\right)$ of $E-3 \mathrm{~d}\left(2 \cdot 10^{-5} \mathrm{~mol} \mathrm{~L}^{-1}\right)$ in DMF (1) and after the addition of $\mathrm{Me}_{4} \mathrm{NOH}$ in the molar ratio of $1: 20$ (2) and $\mathrm{CH}_{3} \mathrm{COOH}(0.1 \mathrm{~N}$ in DMF) (3).

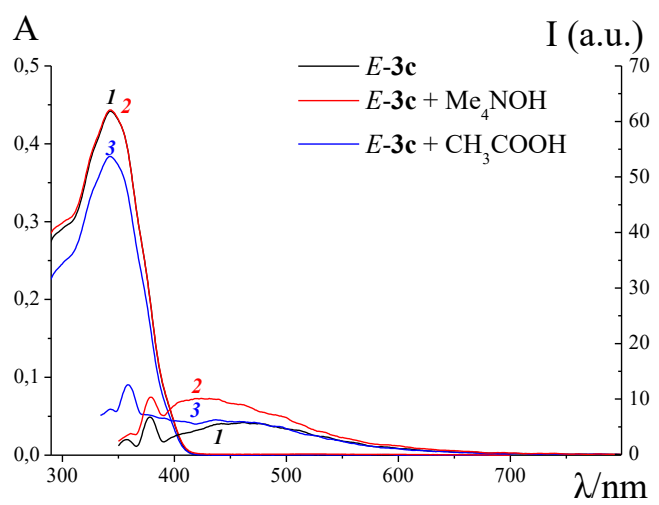

Figure 4. The electron absorption and fluorescence emission spectra $\left(\lambda_{\text {ex }}{ }^{343} \mathrm{~nm}\right)$ of $E-3 \mathrm{c}\left(2 \cdot 10^{-5} \mathrm{~mol} \mathrm{L^{- }}\right.$ $\left.{ }^{1}\right)$ in $\mathrm{DMF}(1)$ and after the addition of $\mathrm{Me}_{4} \mathrm{NOH}$ in the molar ratio of $1: 20(2)$ and $\mathrm{CH}_{3} \mathrm{COOH}(0.1 \mathrm{~N}$ in DMF) (3).

Another confirmation of ESIPT-luminescence of E-3a is its quenching in the process of the spectrophotometric titration of solutions with acetic acid $\left(0.1 \mathrm{~N} \mathrm{CH}{ }_{3} \mathrm{COOH}\right)$, accompanied by the disappearance of the maximum in $\lambda_{\max }$ at $600 \mathrm{~nm}$ in their emission spectra (S-Fig. 3). Similar changes were observed earlier for $E-3 g$ and its alkoxy derivatives ${ }^{11}$. The well known cause of ESIPT-luminescence quenching in such photoacids as aromatic alcohols is rapid reprotonation of any excited alcoholate ion under acidic conditions ${ }^{13}$.

The absence of any changes in absorption and emission band positions in optical spectra of ortho and para hydroxy derivative E-3b, E-3e and E-3f indicates the presence of the excited undissociated phenol forms having a normal emission with maximum at $420-485 \mathrm{~nm}$ in steady-state neutral and acid solutions. At the same time, their basic solutions demonstrate a tendency to tautomeric transformations under more stringent conditions.

The positions of the absorption and emission bands in the optical spectra of $E-\mathbf{3 c}$ and $E$-3d in steady-state neutral, basic and acidic solutions remain unchanged as well, but the causes of these observed phenomena are different. The lack of conjugation between the hydroxy group and the chromophoric system of the heterocycle $E$-3c proved to be the main reason for the existence of only excited undissociated phenol form in irradiated solutions at various acidity and basicity values (Fig. 4). On the contrary, electro-negative amino group included in the common conjugated system of $(E)-2$-(hydroxyarylethenyl)-3-phenylquinazolin-4(3H)ones $E$-3d successfully competes for the binding of a proton (cation) with diazinone cycle during the formation of the zwitterionic, morpholinium cationic (a) and phenolate-anion (b) forms in neutral, acidic and basic media (Scheme 2, Table 2, Fig. 3). This is obviously the main reason for inhibiting the formation of quinonoid form $E$ $\mathbf{4 d}$ in basic media in the ground state.

\section{Photochemical properties of chromophores 3}

The tendency of $E-3$ ligands to photoinduced $E-Z$ isomerization has been investigated by ultraviolet light irradiating (365-nm wavelength band, mercury lamp) of their DMF solutions and estimated by absorption and fluorescence spectroscopy. The $E$-isomers $\mathbf{3 a}, \mathbf{b}, \mathbf{e}, \mathbf{f}$ have been found to demonstrate reverse $E-Z-E$ 
photo/thermal isomerization in a neutral medium, identical to $E-\mathbf{3} \mathbf{g}^{10,11}$. The $E-Z$ isomerization process has been accompanied by a decrease in the intensity of the absorption band to a photostationary state (PSS) with characteristic isobestic points on the absorption titration curves in their UV-Vis spectra. The formation of the $Z$-isomer has been confirmed by the appearance of doublets of the vicinal protons of the $\mathrm{C}=\mathrm{C}$ bond in the range of $\delta$ 5.9-6.6 ppm with a spin-spin interaction constant of $12.5 \mathrm{~Hz}$ in ${ }^{1} \mathrm{H}-\mathrm{NMR}$ spectra, for example, of irradiated solutions of 3a in DMSO-d $d_{6}$ (experimental Section, S-Fig. 4).

According to spectroscopic studies, the nature of the introduced substituents in the para/ortho position to the $\mathrm{OH}$ group of phenols $E-3$ has a substantial effect on the time required to achieve a PSS. So the electron donor substituents of $E-3 a, E-3 e$ and $E-3 f$ provide a commensurate with $E-3 g$ rate of $E-Z$ isomerization in DMF about 16 - $20 \mathrm{~s}$ (Table 2), whereas the presence of an electron-withdrawing nitro group in $E$-3b leads to a significant deceleration of isomerization from 16 to $180 \mathrm{~s}$. The reversible thermal Z-E isomerization has passed by solution thermostating at $75^{\circ} \mathrm{C}$ similarly $E$-3g (S-Fig. 4). In general, the time of the dark $Z$ - $E$ isomerization (30-40 $\mathrm{m}$ ) of diazinones $\mathbf{3} \mathbf{a}, \mathbf{b}$ and $\mathbf{3} \mathbf{f}$ comparable to that for previously studied derivative $E-\mathbf{3}^{10,11}$, while the reaction time of the para-hydroxy substituted $3 \mathbf{e}$ is doubled (Table 1).

The meta position of the $\mathrm{OH}$ group in the chromophore $E-3 c$ hasn't practically an effect on the rate of photoinduced $E-Z$ isomerization but completely inhibits the reversible thermal $Z-E$ isomerization process, i.e. the photoisomerization reaction in this compound becomes irreversible.

According to the spectral data, the morpholino-substituted $E$-3d in the irradiated solutions has not isomerized. Apparently, the action of the amino group associated with the formation of morpholinium zwitterion $\mathbf{D}$ is aimed at stabilization of the trans geometry of excited molecules and, accordingly, a complete PSS equilibrium shift from the photochemical toward the competitive photophysical processes in chromophore solutions. Moreover, the competitive proton transfer to the amino group of the phenolic fragment, rather than the $\mathrm{C}=\mathrm{O}$ and $\mathrm{C}=\mathrm{N}$ heterocycle groups ${ }^{10}$, can also be a determining factor in the slowing or inhibition of photo/thermal isomerization processes (Table 1). A possible competitive photoinduced transfer of a proton to nitro group as a result of the electron density shift in the phenolic fragment with the formation of 4-oxocyclohexa-2,5-dienylideneazinic acid residue is a probable cause of a significant slowdown in the photoisomerization reaction of $E-3 \mathbf{b}$. In favor of the probable proton transfer to the amino or nitro group of the phenolic fragment, quantum-chemical calculations of HOMO and LUMO of E-3b,d show the localization of the electron density on the phenolic fragment involving the above substituents (S-Table 3 ) and the smallest values of the band gap energy.

The hindered transfer of the proton to the heterocycle due to the large spatial distance between the hydroxy group and the diazinonic fragment can be an explanation of deceleration in thermal Z-E isomerization of 3e. The lack of conjugation and the similar remoteness of the $\mathrm{OH}$ group is, apparently, the main reason for the inhibition of thermal isomerization in $E-3 c$ molecules.

\section{Conclusions}

In summary, the spectroscopic studies of the synthesized E-isomers of 2-(arylethenyl)-3-phenylquinazoline$4(3 H)$-ones 3a-f with various acceptor and donor functional groups $(+M)$ into the ortho, para and meta position of the phenolic fragment allowed to establish the correlation between structural features of molecules and their photophysical and photochemical properties. It is shown that the ortho and para positions of the $\mathrm{OH}$ group included in the conjugated chromophoric system lead to a significant broadening of the emission band in the $400-700 \mathrm{~nm}$ range. Moreover, the ortho position of the $\mathrm{OH}$ group is an important factor 
in the successful operation of the photoswitches $\mathbf{3 a}$ and $\mathbf{3 f}$, i.e. reversible photo/thermal $E$-Z-E isomerization. In this case, the most optimal conditions for the transfer of a proton to the spatially-close electronegative diazinone cycle and back in the isomerization process are formed in the conjugate system. The ortho position of the $\mathrm{OH}$ group is also the crucial factor in the photophysical transformations associated with ESIPTluminescence. The transfer of a proton from the $\mathrm{OH}$ group to a heterocycle in the chloro-substituted $E$-3a apparently provides the coherence of the action of photochemical ( $E-Z$ isomerization) and photophysical (ESIPT-luminescence) transformations. On the contrary, the competitive binding of a proton by an electronegative amino group in morpholino-substituted $E$-3d results in a shift in the equilibrium toward photophysical transformations (ESIPT luminescence) and inhibition of photochemical isomerization. As a whole, the data obtained allow us to consider these compounds as potential components for supramolecular ionic devices and white light-emitting organic materials ${ }^{17}$ in the field of molecular ionics. ${ }^{18}$

\section{Experimental Section}

General. IR spectra were registered on IR-Fourier spectrometer PerkinElmer Spectrum One using diffuse reflectance sampling accessory (DRA). Electron absorption spectra were recorded on a UV-2600 PC doublebeam spectrophotometer (Shimadzu, Japan) in the range of 190-700 nm with the wavelength setting accuracy of $\pm 0.3 \mathrm{~nm}$ using a Shimadzu scan standard program UVProbe. Fluorescent spectra were recorded on a Varian Cary Eclipse fluorescence spectrophotometer with mutually perpendicular beams, the wavelength setting accuracy of $0.5 \mathrm{~nm}$. Quartz cuvette SUPRASIL 111-QS 10 ("Hellma", Germany) were used for recording in the range 190-800 $\mathrm{nm}$, the bandwidth around the stationary point of excitation and emission was $10 \mathrm{~nm}$. The excitation point wavelength was set based on the maximum in absorption and emission spectra, the emission point wavelength, based on the maximum in excitation spectra. In spectra luminescence of solvents was taken into account. The relative quantum yields of solutions of compounds 3 were measured at $22 \pm 1^{\circ} \mathrm{C}$ by the method available on www.jyhoriba.co.uk (Jobin Yvon Ltd. 2 Dalston Gardens, Stanmore, Middlesex HA7 1BQ UK). Samples of comparison were fluorescein $\left(\Phi_{\mathrm{abs}}=0,85^{1}\right)$ in $0.1 \mathrm{~N}$ aqueous solution of $\mathrm{KOH}$ and quinine bisulfate $\left(\Phi_{\mathrm{abs}}=0,546^{14}\right)$ in $0.1 \mathrm{~N}$ aqueous $\mathrm{H}_{2} \mathrm{SO}_{4}$ solution. NMR spectra the ${ }^{1} \mathrm{H}$ and ${ }^{13} \mathrm{C}$ were recorded in DMSO- $d_{6}$ solution on devices "Bruker DRX-400" (400 and $100 \mathrm{MHz}$ ) and "Bruker AVANCE-500" (500 and 126 $\mathrm{MHz}$ ) using TMS and DMSO- $d_{6}\left(\delta \mathrm{C} 39.5 \mathrm{pps}\right.$ ) as an internal standard. Full assignment of signals in ${ }^{1} \mathrm{H}$ and ${ }^{13} \mathrm{C}$ NMR spectra performed using two-dimensional experiments ${ }^{1} \mathrm{H}-{ }^{1} \mathrm{H}$ COSY, ${ }^{1} \mathrm{H}-{ }^{1} \mathrm{H}$ NOESY, ${ }^{1} \mathrm{H}-{ }^{13} \mathrm{C}$ HSQC and HMBC. Melting point was determined on the microheating table "Boetius". TLC was performed on plates Silufol UV-254. The spot was shown the light of a low pressure mercury lamps (6 watts) or iodine vapor. The 2methyl-3,1-benzoxazin-4-one was prepared by boiling anthranilic acid in freshly distilled acetic anhydride ${ }^{15}$.

2-Methyl-3-phenylquinazolin-4(3H)-one (1c) The synthesis was carried out by the method described in. ${ }^{10}$ Analytical characteristics of the compound were consistent with literature data.

Aniline $(0.7 \mathrm{~g}, 7.5 \mathrm{mmol})$ and $\mathrm{P}_{2} \mathrm{O}_{5}(1 \mathrm{~g})$ were added to 2-methyl-3,1-benzoxazin-4-one $(1.2 \mathrm{~g}, 7.5 \mathrm{mmol})$ in pyridine $(15-20 \mathrm{~mL})$. The reaction mixture was heated for $26 \mathrm{~h}$ at $90-95{ }^{\circ} \mathrm{C}$. After the reaction reached completion, the solvent was evaporated; water $(50 \mathrm{~mL})$ was added to the residue. The product was filtered off and purified on a chromatographic column $\left(\mathrm{SiO}_{2}\right)$, eluent ethyl acetate-hexane, 3:2. The yield was $1.5 \mathrm{~g}$ (89\%). Analytical characteristics of this compound agreed with those given in the literature. ${ }^{10}$

(E)-2-Styrilquinazolin-4(3H)-ones (3). $1.7 \mathrm{mmol}$ of the corresponding aldehyde $2 \mathrm{a}-\mathrm{f}$ and equimolar amount of $\mathrm{H}_{3} \mathrm{BO}_{3}(1.3 \mathrm{mmol})$ were added to $0.3 \mathrm{~g}(1.3 \mathrm{mmol})$ of compound 1 in acetic acid $(30 \mathrm{ml})$. The reaction mixture 
was boiled for 6-8 hours. After completion of the reaction, the solvent was distilled off. The product has been purified by column chromatography from various impurities and $Z$-isomer formed in small quantities in the synthesis process (2-7\%). Chromatographic separation was carried out on a column $\left(\mathrm{SiO}_{2}\right)$, making eluent with a mixture of ethyl acetate and hexane, gradient changing the ratio of the concentrations of solvents from 1:4 to 4:1, respectively. Target product was crystallized from $\mathrm{EtOH}$ or $\mathrm{CH}_{3} \mathrm{CN}$ (3a-f).

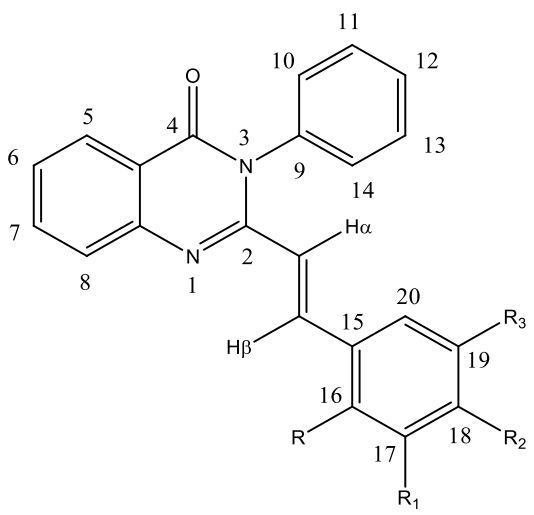

(E)-2-(5-Chloro-2-hydroxystyryl)-3-phenylquinazolin-4(3H)-one (3a). Pale yellow, yield $330 \mathrm{mg}$ (72\%), $\mathrm{mp} 309$ - $311^{\circ} \mathrm{C}\left(\mathrm{CH}_{3} \mathrm{CN}\right) ;{ }^{1} \mathrm{H}$ NMR (500 MHz, DMSO-d $\left.d_{6}\right) \delta / \mathrm{ppm} 10.44$ (s, $\left.1 \mathrm{H}, \mathrm{OH}\right), 8.13$ (d.d, J 8.0, $\left.1.3 \mathrm{~Hz}, 1 \mathrm{H}, \mathrm{H}-5\right), 7.95$ (d, J $15.6 \mathrm{~Hz}, 1 \mathrm{H}, \mathrm{HB}$ ), 7.87 (d.d.d, J 8.1, 7.0, 1.3 Hz, 1H, H-7), 7.77 (d, J 8,0 Hz, 1H, H-8), $7.55-7.63(\mathrm{~m}, 3 \mathrm{H}, \mathrm{H}-$ 11, H-13, H-12), 7.53 (d.d.d, J 8.0, 7.0, 1.0 Hz, 1H, H-6), 7.45 (m, 2H, H-10, H-14), 7.19 (d, J 2,5 Hz, 1H, H-20), 7.18 (d.d, J 8.5, $2.5 \mathrm{~Hz}, 1 \mathrm{H}, \mathrm{H}-18$ ), 6.84 (d, J $8.5 \mathrm{~Hz}, 1 \mathrm{H}, \mathrm{H}-17$ ), 6.63 (d, J $15.6 \mathrm{~Hz}, 1 \mathrm{H}, \mathrm{H \alpha}$ ); ${ }^{13} \mathrm{C} \mathrm{NMR}(126 \mathrm{MHz}$, DMSO-d $\left.d_{6}\right) \delta /$ ppm 161.77, 155.94, 152.37, 147.89, 137.59, 135.17, 134.51, 130.54, 130.05 (2), 129.52, 129.41 (2), 128.77, 127.63, 126.92, 126.87, 123.88, 123.25, 122.10, 120.99, 118.21. IR(DRA): 695, 721, 762, 812, 849, $898,976,1015,1113,1169,1246,1282,1306,1337,1352,1425,1470,1492,1550,1572,1633,1666,3047$, $3310 \mathrm{~cm}^{-1}$; Anal. Calcd for $\mathrm{C}_{22} \mathrm{H}_{15} \mathrm{ClN}_{2} \mathrm{O}_{2}: \mathrm{C}, 70.50 ; \mathrm{H}, 4.03 ; \mathrm{N}, 7.47$, Cl, 9.46. Found: C, 70.58; H, 3.84; N, 7.13.

(Z)-2-(5-chloro-2-hydroxystyryl)-3-phenylquinazolin-4(3H)-one (Z-3a). ${ }^{1} \mathrm{H}$ NMR (DMSO- $d_{6}$ ) $\delta / p p m: 10.04$ (s, $1 \mathrm{H}, \mathrm{OH}$ ), 8.15 (d.d, J 8.3, 1.2 Hz, $1 \mathrm{H}, \mathrm{H}-5$ ), 7.81 (d.d.d, J 8.4, 6.9, $1.5 \mathrm{~Hz}, 1 \mathrm{H}, \mathrm{H}-7), 7.49-7.55$ (m, 3H, H-11, H13, H-12 H-8, H-6), 7.47 (d, J 2,6 Hz, 1H, H-20), 7.40 (m, 2H, H-10, H-14), 7.13 (d.d, J 8.7, 2.6 Hz, 1H, H-18), 6.76 (d, J $8.7 \mathrm{~Hz}, 1 \mathrm{H}, \mathrm{H}-17), 6.62(\mathrm{~d}, J 12.5 \mathrm{~Hz}, 1 \mathrm{H}, \mathrm{HB}) 5.92(\mathrm{~d}, J 12.5 \mathrm{~Hz}, 1 \mathrm{H}, \mathrm{H \alpha}$ ).

The quinonoid form E-4a (a solution of $E$-3a in a 20 -fold excess of the base $\left(\mathrm{Me}_{4} \mathrm{NOH} \cdot 5 \mathrm{H}_{2} \mathrm{O}\right.$ )): ${ }^{1} \mathrm{H}$ NMR (DMSO$d_{6}, 500 \mathrm{MHz}$ ) $\delta / \mathrm{ppm}: 8.76$ (br.d, J 8.2 Hz, 1H, H-8), 7.92 (br.d.d, , J 7.7, J $\left.1.6 \mathrm{~Hz}, 1 \mathrm{H}, \mathrm{H}-5\right), 7.44$ (d, J $16.0 \mathrm{~Hz}, 1 \mathrm{H}$, $\mathrm{HB}$ ), $7.19(\mathrm{~m}, 2 \mathrm{H}, \mathrm{H}-11, \mathrm{H}-13$ ), 7.11 (d.d.d, $J=8.5,6.8,1.5 \mathrm{~Hz}, 1 \mathrm{H}, \mathrm{H}-7), 6.87$ (t.t. $J=7.3,1.1 \mathrm{~Hz}, 1 \mathrm{H}, \mathrm{H}-12$ ), $6.72-6.79(\mathrm{~m}, 4 \mathrm{H}, \mathrm{H}-6, \mathrm{H}-10, \mathrm{H}-14, \mathrm{H \alpha}), 6.65(\mathrm{~d}, J=3.0 \mathrm{~Hz}, 1 \mathrm{H}, \mathrm{H}-20),$,6.59 (d.d, J = 8.9, 3.0 Hz, $1 \mathrm{H}, \mathrm{H}-18$ ), $6.01(\mathrm{~d}, J 8.9 \mathrm{~Hz}, 1 \mathrm{H}, \mathrm{H}-17)$.

(E)-2-(2-Hydroxy-5-nitrostyryl)-3-phenylquinazolin-4(3H)-one (3b). Yellow, yield $440 \mathrm{mg}$ (92\%), mp 351 - 353 $\mathrm{C}(\mathrm{DMF}) ;{ }^{1} \mathrm{H}$ NMR $\left(500 \mathrm{MHz}, \mathrm{DMSO}-d_{6}\right) \delta / \mathrm{ppm} 11.78(\mathrm{~s}, 1 \mathrm{H}, \mathrm{OH}$ ), 8.12 (d.d, J 8.0, $1.0 \mathrm{~Hz}, 1 \mathrm{H}, \mathrm{H}-5), 8.10$ (d, J 2.8 $\mathrm{Hz}, 1 \mathrm{H}, \mathrm{H}-20$ ), 8.06 (d.d, J 9.0, $2.8 \mathrm{~Hz}, 1 \mathrm{H}, \mathrm{H}-18$ ), 8.02 (d, J $15.6 \mathrm{~Hz}, 1 \mathrm{H}, \mathrm{HB}$ ), 7.89 (d.d.d, J 8.1, 7.0, $1.5 \mathrm{~Hz}, 1 \mathrm{H}, \mathrm{H}-$ 7), 7.80 (d, J $8.1 \mathrm{~Hz}, 1 \mathrm{H}, \mathrm{H}-8), 7.59-7.65$ (m, 3H, H-11, H-12, H-13), 7.54 (d.d.d, J 8.0, 7.0, 1.0 Hz, 1H, H-6), 7.47 (m, 2H, H-10, H-14), 6.98 (d, J 9.0 Hz, 1H, H-17), 6.75 (d, J $15.6 \mathrm{~Hz}, 1 \mathrm{H}, \mathrm{H \alpha}$ ); ${ }^{13} \mathrm{C}$ NMR (126 MHz, DMSO-d $)_{6}$ ס/ppm 162.32, 161.21, 151.55, 147.30, 139.69, 137.04, 134.68, 133.32, 129.57 (2), 129.07, 128.92 (2), 127.19, 126.56, 126.37, 125.99, 125.13, 122.87, 122.19, 120.57, 116.49. IR(DRA): 699, 721, 736, 750, 771, 832, 855, $900,911,977,1015,1085,1120,1170,1239,1251,1288,1340,1365,1439,1469,1494,1518,1553,1586$, 1637, 1660, 3011, 3082, $3234 \mathrm{~cm}^{-1}$; Anal. Calcd for $\mathrm{C}_{22} \mathrm{H}_{15} \mathrm{~N}_{3} \mathrm{O}_{4}: \mathrm{C}, 68.57 ; \mathrm{H}, 3.92 ; \mathrm{N}, 10.90$. Found: $\mathrm{C}, 68.24 ; \mathrm{H}$, 3.63; N, 10.81 . 
(E)-2-(3-Hydroxystyryl)-3-phenylquinazolin-4(3H)-one (3c). White, yield $240 \mathrm{mg}(67 \%), \mathrm{mp} 272-274^{\circ} \mathrm{C}$ $\left(\mathrm{CH}_{3} \mathrm{CN}\right.$ ); ${ }^{1} \mathrm{H}$ NMR $(500 \mathrm{MHz}$, DMSO-d $)$ )/ppm 9.57 (s, $\left.1 \mathrm{H}, \mathrm{OH}\right), 8,13$ (d.d, J 8.0, 1,0 Hz, 1H, H-5), 7.87 (d.d.d, J 8.0, 7.0, 1.5 Hz, 1H, H-7), 7.79 (d, J $15.5 \mathrm{~Hz}, 1 \mathrm{H}, \mathrm{H \beta}$ ), 7.78 (d, J $7.9 \mathrm{~Hz}, 1 \mathrm{H}, \mathrm{H}-8$ ), $7.57-7.64(\mathrm{~m}, 3 \mathrm{H}, \mathrm{H}-11, \mathrm{H}-12$, H-13), 7.53 (d.d.d, J 8.0, 7.0, 1.0 Hz, 1H, H-6), 7.47 (m, $2 \mathrm{H}, \mathrm{H}-10, \mathrm{H}-14$ ), 7.15 (t, J $7.8 \mathrm{~Hz}, 1 \mathrm{H}, \mathrm{H}-19), 6.79$ (d, J $7.7 \mathrm{~Hz}, 1 \mathrm{H}, \mathrm{H}-20$ ), 6.74 (d.d, J 8.0, $1.7 \mathrm{~Hz}, 1 \mathrm{H}, \mathrm{H}-18$ ), 6.68 (br.s, $1 \mathrm{H}, \mathrm{H}-16$ ), 6.24 (d, J $15.5 \mathrm{~Hz}, 1 \mathrm{H}, \mathrm{H \alpha}$ ); ${ }^{13} \mathrm{C} \mathrm{NMR}$ $\left(126 \mathrm{MHz}, \mathrm{DMSO}-d_{6}\right) \delta / p p m$ 161.25, 157.66, 151.32, 147.38, 138.96, 137.02, 136.05, 134.74, 130.05, 129.66 (2), 129.20, 128.93 (2), 127.17, 126.56, 126.41, 120.57, 119.67, 118.98, 117.13, 113.11. IR(DRA): 691, 762, 779, $845,952,980,1017,1121,1177,1243,1281,1337,1382,1431,1452,1472,1547,1571,1594,1651,3031$, $3166 \mathrm{~cm}^{-1}$; Anal. Calcd for $\mathrm{C}_{22} \mathrm{H}_{16} \mathrm{~N}_{2} \mathrm{O}_{2}$ : C, 77.63; $\mathrm{H}, 4.74 ; \mathrm{N}, 8.23$. Found: $\mathrm{C}, 77.67 ; \mathrm{H}, 4.60 ; \mathrm{N}, 8.24$.

(E)-2-(2-Hydroxy-5-morpholinostyryl)-3-phenylquinazolin-4(3H)-one (3d). White, yield $230 \mathrm{mg}$ (52\%), mp 255 - $257^{\circ} \mathrm{C}\left(\mathrm{CH}_{3} \mathrm{CN}\right) ;{ }^{1} \mathrm{H}$ NMR (500 MHz, DMSO-d $)$ )/ppm 9.59 (s, $\left.1 \mathrm{H}, \mathrm{OH}\right), 8.11$ (d.d, J 7.9, $\left.1.2 \mathrm{~Hz}, 1 \mathrm{H}, \mathrm{H}-5\right), 7.96$ (d, J $15.5 \mathrm{~Hz}, 1 \mathrm{H}, \mathrm{H \beta}$ ), 7.86 (d.d.d, J 8.1, 7.0, J $1.5 \mathrm{~Hz}, 1 \mathrm{H}, \mathrm{H}-7), 7.76$ (d, J 8.0 Hz, 1H, H-8), $7.55-7.63(\mathrm{~m}, 3 \mathrm{H}, \mathrm{H}-$ 11, H-12, H-13), 7.51 (d.d.d, J 7.9, 7.0, J $0.9 \mathrm{~Hz}, 1 \mathrm{H}, \mathrm{H}-6), 7.44$ (m, 2H, H-10, H-14), 6.84 (d.d, J 8.8, $2.8 \mathrm{~Hz}, 1 \mathrm{H}$, $\mathrm{H}-18$ ), 6.73 (d, J $8.8 \mathrm{~Hz}, 1 \mathrm{H}, \mathrm{H}-17), 6.67$ (d, J $2.8 \mathrm{~Hz}, 1 \mathrm{H}, \mathrm{H}-20), 6.60$ (d, J $15.5 \mathrm{~Hz}, 1 \mathrm{H}, \mathrm{H \alpha}$ ), 3.69 and 2.87 (both t, J $\left.4.5 \mathrm{~Hz}, 8 \mathrm{H}, \mathrm{NC}_{4} \underline{\mathrm{H}}_{8} \mathrm{O}\right) ;{ }^{13} \mathrm{C} \mathrm{NMR}(126 \mathrm{MHz}$, DMSO-d $\left.)\right) \delta / \mathrm{ppm} 161.34,152.36,150.72,147.60,144.18,137.33$, $136.29,134.68,129.54$ (2), 128.95 (2), 128.88, 127.05, 126.40, 126.20, 121.57, 120.46, 120.44, 119.81, 116.70, 116.31, 66.11 (2), 49.77 (2). IR(DRA): 694, 727, 767, 831, 888, 925, 987, 1016, 1121, 1182, 1219, 1252, 1272, $1302,1359,1433,1474,1532,1574,1625,1687,2854,2956,3066,3226 \mathrm{~cm}^{-1}$; Anal. Calcd for $\mathrm{C}_{26} \mathrm{H}_{23} \mathrm{~N}_{3} \mathrm{O}_{3}: \mathrm{C}_{\text {, }}$ 73.39; $H, 5.45 ; N, 9.88$. Found: C, 72.99; H, 5.48; N, 9.73 .

(E)-2-(4-Hydroxy-3-methoxystyryl)-3-phenylquinazolin-4(3H)-one (3e). White, yield $220 \mathrm{mg}$ (56\%), mp 281 $283^{\circ} \mathrm{C}\left(\mathrm{CH}_{3} \mathrm{CN}\right) ;{ }^{1} \mathrm{H}$ NMR $\left(500 \mathrm{MHz}, \mathrm{DMSO}-d_{6}\right) \delta / p p m 9.53$ (s, $\left.1 \mathrm{H}, \mathrm{OH}\right), 8.12$ (d.d, J 8.1, $\left.1.2 \mathrm{~Hz}, 1 \mathrm{H}, \mathrm{H}-5\right), 7.86$ (d.d.d, J 8.1, 7.0, 1.6 Hz, 1H, H-7), $7.81(\mathrm{~d}, J 15.4 \mathrm{~Hz}, 1 \mathrm{H}, \mathrm{H \beta}), 7.73(\mathrm{~d}, J 8.0 \mathrm{~Hz}, 1 \mathrm{H}, \mathrm{H}-8), 7.58-7.63(\mathrm{~m}, 3 \mathrm{H}, \mathrm{H}-$ 11, H-12, H-13), 7.51 (d.d.d, J 8.0, 7.0, $0.8 \mathrm{~Hz}, 1 \mathrm{H}, \mathrm{H}-6), 7.46(\mathrm{~m}, 2 \mathrm{H}, \mathrm{H}-10, \mathrm{H}-14), 6.91(\mathrm{~d}, J 1.7 \mathrm{~Hz}, 1 \mathrm{H}, \mathrm{H}-16)$, 6.79 (d.d, J 8.1, $1.7 \mathrm{~Hz}, 1 \mathrm{H}, \mathrm{H}-20), 6.74$ (d, J $8.1 \mathrm{~Hz}, 1 \mathrm{H}, \mathrm{H}-19), 6.08$ (d, J $15.4 \mathrm{~Hz}, 1 \mathrm{H}, \mathrm{H \alpha}$ ), $3.71\left(\mathrm{~s}, 3 \mathrm{H}, \mathrm{OC} \underline{H}_{3}\right) ;{ }^{13} \mathrm{C}$ NMR $\left(126 \mathrm{MHz}\right.$, DMSO- $\left.d_{6}\right)$ d/ppm 161.25, 151.84, 151.77, 147.71, 147.55, 139.35, 137.14, 134.65, 129.56 (2), $128.99,128.92$ (2), 126.92, 126.39, 126.37, 126.13, 120.67, 120.36, 116.57, 115.91, 111.88, 55.45. IR(DRA): 689, 759, 772, 807, 835, 908, 975, 1016, 1037, 1119, 1132, 1165, 1213, 1261, 1286, 1340, 1361, 1400, 1469, $1516,1542,1598,1657,2839,2956,3013,3065,3319 \mathrm{~cm}^{-1}$; Anal. Calcd for $\mathrm{C}_{23} \mathrm{H}_{18} \mathrm{~N}_{2} \mathrm{O}_{3}: \mathrm{C}, 74.58 ; \mathrm{H}, 4.90 ; \mathrm{N}$, 7.56. Found: C, 74.49; H, 4.69; N, 7.51 .

(E)-2-(3,5-Di-tert-butyl-2-hydroxystyryl)-3-phenylquinazolin-4(3H)-one (3f). White, yield $230 \mathrm{mg}(48 \%), \mathrm{mp}$ $214-216^{\circ} \mathrm{C}\left(\mathrm{CH}_{3} \mathrm{CN}\right) ;{ }^{1} \mathrm{H}$ NMR $(500 \mathrm{MHz}$, DMSO-d $\left.)\right) \delta / p p m 8.90(\mathrm{~s}, 1 \mathrm{H}, \mathrm{OH}), 8.25$ (d, J $\left.15.4 \mathrm{~Hz}, 1 \mathrm{H} \beta\right), 8.15$ (d.d, J 8.1, $1.1 \mathrm{~Hz}, 1 \mathrm{H}-5$ ), 7.88 (d.d.d, J 8.1, 7.0, $1.5 \mathrm{~Hz}, 1 \mathrm{H}, \mathrm{H}-7$ ), 7.77 (d, J $8.1 \mathrm{~Hz}, 1 \mathrm{H}, \mathrm{H}-8$ ), $7.58-7.65(\mathrm{~m}, 3 \mathrm{H}, \mathrm{H}-11$, $\mathrm{H}-12, \mathrm{H}-13), 7.53$ (d.d.d, J 8.0, 7.0, $0.9 \mathrm{~Hz}, 1 \mathrm{H}, \mathrm{H}-6), 7.46$ (m, 2H, H-10, H-14), 7.19 (d, J 2.2 Hz, 1H, H-18), 6.79 (d, J $2.2 \mathrm{~Hz}, 1 \mathrm{H}, \mathrm{H}-20), 6.14$ (d, J 15.4, Hz, $1 \mathrm{H}, \mathrm{H \alpha}), 1.34\left(\mathrm{~s}, 9 \mathrm{H}, 3 \mathrm{C}_{3}\right), 1.12\left(\mathrm{~s}, 9 \mathrm{H}, 3 \mathrm{C}_{3}\right) ;{ }^{13} \mathrm{C} \mathrm{NMR}(126 \mathrm{MHz}$,

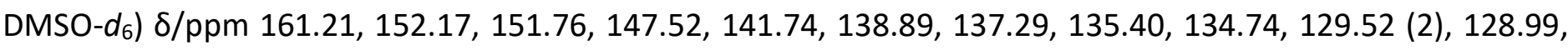
128.88 (2), 127.02, 126.43, 126.28, 125.20, 124.62, 120.48, 119.96, 119.26, 34.72, 33.77, 31.00 (3), 29.66 (3). IR(DRA): 699, 724, 781, 879, 957, 970, 1018, 1025, 1128, 1175, 1209, 1232, 1280, 1302, 1359, 1431, 1441, $1469,1490,1542,1574,1624,1680,2872,2962,2999,3030,3062,3251 \mathrm{~cm}^{-1}$; Anal. Calcd for $\mathrm{C}_{30} \mathrm{H}_{32} \mathrm{~N}_{2} \mathrm{O}_{2}: \mathrm{C}_{\text {, }}$ 79.61; H, 7.13; N, 6.19. Found: C, 79.48; H, 7.19; N, 6.27.

Investigation of photophysical and photochemical properties of 3a-f. Solvents were distilled and dried according to standard procedures. The irradiation was carried out with a $250 \mathrm{~W}$ mercury ball gas discharge lamp DRSh-250 with a concave mirror and a quartz lens for focusing radiation at the cuvette. To irradiate and obtain absorption and luminescence spectra, Hellma QS-111 quartz cuvettes with a rubbed lid were used, the optical path length was $1 \mathrm{~cm}$. The cuvettes were placed in the focus of the photoreactor. Air is used for cooling 
cells and reactor. The desired range of light was allocated by means of filters SZS-7 (thermal filter) and UFS- 6 (UV filter). The total power of the light flux after the filters was $150 \mathrm{~mW}$, determined using a meter of average power and energy of laser radiation IMO- $2 \mathrm{~N}^{16}$. The luminous flux was directed to the meter by means of quartz optical fibers.

\section{Kinetic studies using absorption spectroscopy}

1. The control of photochemical transformations of E-3a-c,e-f $\left(2 \cdot 10^{-5} \mathrm{M}\right)$ in $n$-butanol, acetonitrile and DMF and $E$-3d in THF was carried out by recording the uv spectra of irradiated solutions every 2 seconds (up to photostationary state (PSS) of solutions).

2. The control of the thermal transformation of the photostationary solutions $Z-3\left(2 \cdot 10^{-5} \mathrm{M}\right)$ thermostated at $75{ }^{\circ} \mathrm{C}$ was carried out by registration of UV spectra every 10 minutes. The choice of temperature is determined by ${ }^{10}$.

3. Spectrophotometric titration of solutions $E-3 \mathbf{a}, \mathbf{b}, \mathbf{e}, \mathbf{f}\left(2 \cdot 10^{-5} \mathrm{M}\right)$ by strong bases $\mathrm{Me}_{4} \mathrm{NOH}$ or $t$-BuOK was carried out until unchanged state using a series of solutions with a concentration ratio of $C_{E-3}$ : $C_{\text {base }}$ from 1:1 to $1: 25$.

Kinetic studies using NMR. The $1 \mathrm{ml}$ of DMSO- $d_{6}$ solution of $0.06 \mathrm{mmol} E-3$ was prepared. Monitoring of photochemical transformations of $E-3$ was carried out by recording the ${ }^{1} \mathrm{H}$ NMR spectra of irradiated solutions.

\section{Acknowledgements}

This work was supported by the Russian Foundation for Basic Research (grant 18-03-00112). Analytical studies were carried out using equipment of the Center for Joint Use "Spectroscopy and Analysis of Organic Compounds" at the Postovsky Institute of Organic Synthesis of the Russian Academy of Sciences (Ural Branch).

\section{Supplementary Materials}

${ }^{1} \mathrm{H}$ NMR spectra of $\mathbf{3 a}$ and $\mathbf{3 d}$, luminescence data of compound $\mathbf{3 a}$, energies and structures of HOMO and LUMO of 3a-f are given in the Supplementary Material file associated with this article.

\section{References}

1. Krasovitskii, B. N.; Bolotin, B. M. Organicheskiye Lyuminofory [Organic Luminophores], Khimiya, Moscow. 1984, 340 pp. (in Russian).

https://doi.org/10.1016/j.jorganchem.2013.07.009

2. Irie, M. Chem. Rev. 2000, 1685.

https://doi.org/10.1002/(SICI)1099-0682(199904)1999:4<601::AID-EJIC601>3.0.CO;2-X

3. Lipunova, G. N.; Nosova, E. V.; Trashakhova, T. V.; and Charushin, V. N. Russ. Chem. Rev. 2011, 80, 11151133.

4. Lower, S. K.; El-Sayed, M. A. Chem. Rev. 1966, 66, 199-241.

5. Dabiri, M.; Baghbanzadeh, M.; Delbari, A. S. J. Comb. Chem. 2008, 10, 700-703.

6. Bakalova, S. M.; Gil Santos, A.; Timcheva, I.; Kaneti, J.; Filipova, I. L.; Dobrikov, G. M.; Dimitrov, V. D. J. Mol. Struct. THEOCHEM. 2004, 710, 229-234. 
7. Mashraqui, S. H.; Ghorpade, S. S.; Tripathi, S.; Britto, S. Tetrahedron Lett. 2012, 53, 765-768. https://doi.org/10.1002/anie.201711735

8. Trashakhova, T. V.; Nosova, E. V.; Valova, M. S.; Slepukhin, P. A.; Lipunova, G. N.; Charushin, V. N. J. Org. Chem. 2011, 47, 748-755. https://doi.org/10.3390/ma10070784

9. Nosova, E. V.; Stupina, T. V.; Lipunova, G. N.; Valova, M. S.; Slepukhin, P. A.; Charushin, V. N. Int. J. Org. Chem. 2012, 2, 56-63. https://doi.org/10.1016/j.jorganchem.2010.11.045

10. Ovchinnikova, I. G.; Kim, G. A.; Matochkina, E. G.; Kodess, M. I.; Barykin, N. V.; El'tsov, O. S.; Nosova, E. V.; Rusinov, G. L.; Charushin, V. N. Russ. Chem. Bull. 2014, 63, 2467-2477.

11. Ovchinnikova, I. G.; Kim, G. A.; Matochkina, E. G.; Kodess, M. I.; Slepukhin, P. A.; Kovalev, I. S.; Nosova, E. V.; Rusinov, G. L.; Charushin, V. N. Journal of Photochemistry and Photobiology A: Chemistry 2018, 351, 16-28.

https://doi.org/10.1080/10426500701407417

12. Kumpulainen, T.; Lang, B.; Rosspeintner, A.; Vauthey, E. Chem. Rev. 2017, 117, 10826-10939. https://doi.org/10.1080/10426507.2011.610848

13. Ireland, J. F.; Wyatt, A. H. Adv. Phys. Org. Chem. 1978, 43, 132-215. https://doi.org/10.1021/acs.iecr.6b04292

14. Parker, C. A. Photoluminescence of Solutions, with Applications to Photochemistry and Analytical Chemistry; Elsevier, Amsterdam. 1968, pp 544.

15. Walker, G. N. J. Am. Chem. Soc. 1955, 77, 6698-6699.

16. Luk'yanova, E. L. Izmeritel' srednei moshchnosti i energii lazernogo izlucheniya IMO-2N [IMO-2N Meter of Average Power and Laser Irradiation Energy], Volgograd. 1980 (in Russian).

17. J. Zhao; S. Ji; Y. Chen; H. Guo; P. Yang, Phys. Chem. Chem. Phys. 2012, 14, 8803-8817.

18. J.-M. Lehn, Supramolecular Chemistry. Concepts and Perspectives, VCH: Weinheim, New York, Basel, Cambridge, Tokyo. 1995, pp 271. 